\title{
CS06-01
}

\section{FIRST EXPERIENCE AND LATER RISK OF ALCOHOL DEPENDENCE: AN EPIDEMIOLOGICAL AND GENETIC APPROACH ON A LARGE SAMPLE OF YOUNG ADULTS}

\section{Y. Le Strat, P. Gorwood}

U675, INSERM, Paris, France

Many risk factors for alcohol dependence have been pointed out on the basis of large cohort analyses, including antisocial personality disorder, familial history of substance abuse and initial effect of the first consumption of alcohol, these factors having large overlaps. In addition, a low level of response to first alcohol drink has been reported to increase the risk of future alcoholdependence. This response to first dinks is a genetically influenced characteristic, but the genes involved remain unknown.

The Susceptibility Addiction Gene Environment (SAGE) cohort was designed to assess addictions and psychiatric disorders in a cohort of young adults. All 3.895 college students of the French region "Champagne Ardennes" were eligible. Of them, 3.056 (1.834 males and 1.224 females; mean age 20.42 years, s.d 1.4) were enrolled on their campus during a single day and completed an intake assessment. The final sample was based on 2.730 subjects $(70.08 \%)$ who fulfilled the inclusion criteria, namely having ever drink at least once in their lifetime. The level of response to alcohol during early consumption was assessed, as well as the DSM criteria for alcohol dependence at the time of interview. DNA was also collected.

Our results confirm the strong association between low level of response to alcohol and the risk of dependence. Furthermore, the genotyping of several candidate genes allowed disentangling the potential intermediate factors between the first consumption and the development of later dependence. These findings emphasize the utility of the endophenotype approach in the genetic study of addictive disorders 